\title{
Relative importance of biodiversity and the abiotic environment in mediating an ecosystem process
}

\author{
J. A. Godbold*, M. Solan \\ Oceanlab, Institute of Biological and Environmental Sciences, University of Aberdeen, Newburgh, \\ Aberdeenshire AB41 6AA, UK
}

\begin{abstract}
Whilst there is a wealth of empirical studies that indicate negative ecosystem consequences of biodiversity loss, much debate remains over the existence, strength and importance of the same patterns in natural systems. We used a gradient of organic enrichment as a means of defining non-random species loss in the marine benthos and, using partial linear regression, determined the relative importance of macrofaunal biodiversity and the abiotic environment in affecting a benthic ecosystem process (bioturbation intensity; indicated by sediment mixing depth), that is important in mediating benthic functioning. Of the abiotic and biotic variables tested $(n=8)$, species richness and sediment total organic carbon (TOC) content together explained $65 \%$ of the variability in this ecosystem process, with more than half of this variability explained solely by species richness. Importantly, the relative importance of biodiversity decreased at low levels of species richness and/or high levels of TOC. These results have profound implications for manipulative field experiments, where environmental factors are likely to dominate ecosystem processes, because the extent and importance of biological mediation could be underestimated. Our results also revealed that a large proportion of the explained variability in the ecosystem process is explained by the underlying reciprocal relationship (shared variability) between biodiversity and sediment TOC, highlighting the importance of species-environment interactions. If we are to fully appreciate the role of biodiversity in natural systems, our findings suggest that the intimate relationship between species and their environment needs to be more prominently featured in future studies that consider the ecosystem consequences of biodiversity loss.
\end{abstract}

KEY WORDS: Biodiversity - Ecosystem processes - Species richness $\cdot$ Ecosystem functioning · Partial linear regression · Gradient

\section{INTRODUCTION}

The effects of biodiversity loss on ecosystem processes have now been well established and numerous experimental studies have shown that, irrespective of the system under study, biodiversity loss has a negative effect on ecosystem properties (Balvanera et al. 2006, Cardinale et al. 2006, Worm et al. 2006). There has been much debate and controversy over how realistic the experimental approach for investigating the relationship between biodiversity and ecosystem processes is, due to the highly controlled conditions of the mesocosm environment and the simplifying assumption that species loss is random (e.g. Hooper et al. 2005, Srivastava \& Vellend 2005). Despite the fact that researchers have steadily improved designs to make experimental studies more closely resemble natural systems (see Fig. 1.3 in Godbold 2008, Naeem 2008, Solan et al. 2009), there is a fundamental difference between being able to demonstrate biodiversity effects under assembled conditions and showing that such effects are just as strong and important in natural systems (Srivastava \& Vellend 2005). Observational studies, in which correlations between regional gradients in biodiversity and ecosystem processes are performed (e.g. McNaughton 1993, Wardle et al. 1997), have been valuable in this regard, but direct cause-effect relationships cannot generally be determined because covarying environmental factors (e.g. temperature, soil fertility, rainfall, area, fire frequency) may also affect 
ecosystem processes (Tilman et al. 1997, Grace et al. 2007). A further complication is the debate over whether diversity is the cause or consequence of ecosystem functioning (Flint \& Kalke 2005, Cardinale et al. 2009). Consequently, although there is a long tradition in ecology of recognising that abiotic factors can significantly affect ecosystem functioning (e.g. primary production, Botkin \& Malone 1968), few attempts have been made to determine the relative importance of biodiversity and environmental factors in affecting ecosystem properties in natural systems (but see Grace et al. 2007, Healy et al. 2008) because these ecosystems are structured by multiple and simultaneously operating abiotic and biotic factors that are difficult to dissociate (Angermeier \& Winston 1998). Nonetheless, overcoming these difficulties is an essential step in fully understanding the consequences of altered diversity in natural systems where the role of diversity has likely been understated (Duffy 2009).

Accounting for the effects of (multi)collinearity between explanatory variables and/or spatial autocorrelation between sampling points is not trivial (but see e.g. Galbraith et al. 2008, Jones et al. 2008). Even low amounts of collinearity can bias analyses (Graham 2003), causing inaccurate model parameterisation and decreased statistical power that can lead to ambiguous interpretations of the underlying relationships (Legendre 1993, Legendre \& Legendre 1998, MacNally 2000, Graham 2003). In addition, (multi)collinearity between explanatory variables may result in ecologically more plausible explanatory variables being excluded from, for example, a stepwise multiple regression analysis, if other correlated explanatory variables statistically better explain the observed variability in the response variable (MacNally 2000, Graham 2003). Several approaches can be adopted to overcome problems of collinearity within data from natural systems (e.g. Graham 2003). These range from the exclusion of some of the most collinear variables to using statistical techniques such as variation partitioning (canonical correspondence analysis, Borcard et al. 1992; partial linear regression, Legendre 1993), hierarchical partitioning (Chevan \& Sutherland 1991, Mac Nally 2000), principal components regression (Jolliffe 2002) or structural equation modelling (Grace 2006), but these techniques have seldom been applied within the biodiversityecosystem functioning framework.

Despite the statistical and interpretational drawbacks of investigating natural ecological systems, the use of anthropogenic and natural gradients has been vital for improving our understanding of long-term community and ecosystem dynamics (for review see Fukami \& Wardle 2005). For example, the use of elevation gradients has improved our understanding of the effects of global warming on ecosystem processes such as soil de- composition and nutrient mineralisation (Vitousek et al. 1994). Similarly, $\mathrm{CO}_{2}$ gradients from natural springs have been used to illustrate the long-term effects of $\mathrm{CO}_{2}$ enrichment on the ecosystem storage of carbon and nitrogen (e.g. Ross et al. 2000). Such observational studies, in which the number of confounding factors that may influence ecosystem properties are limited (e.g. Vitousek et al. 1994, Troumbis \& Memtsas 2000), are of vital importance, as long as their limitations are explicitly recognised, because they can allow causal relationships to be inferred (Fukami \& Wardle 2005). Indeed, natural gradients of species diversity have been used to infer how species loss may affect ecosystem functioning, in particular productivity, although confounding factors have not always been constrained (but see Troumbis \& Memtsas 2000, Thompson et al. 2005) and, consequently, results have been variable. Some studies suggest a generally positive relationship between plant diversity and productivity (Troumbis \& Memtsas 2000, Mittelbach et al. 2001), whilst others find no such effect and instead suggest that abiotic factors are more important in natural systems (Wardle et al. 1997, Thompson et al. 2005). Indeed, some (e.g. Huston \& McBride 2002) have argued that productivity is regulated first and foremost by environmental conditions, such as climate and soil composition, and that these make diversity effects so subtle that they can only be detected under highly controlled experimental conditions in which the influence of the environment has been excluded or controlled. Moreover, the scales at which ecosystem processes occur can be radically different to the spatial and temporal scales at which biodiversity operates (Raffaelli 2006). This would suggest that biodiversity effects are unlikely to be detected in natural systems, especially at the regional or global scale (but see Hector et al. 1999, Emmerson et al. 2001), because the variability of any environmental variables outweighs the mediating effects of the biota.

There are instances, however, where environmental variability becomes more predictable and directional, such as along natural and anthropogenic gradients of disturbance. These gradients have been particularly well studied in marine benthic environments, where sequential changes in community composition have been documented alongside concurrent changes in the physicochemical properties of the benthos (e.g. Pearson \& Rosenberg 1978, Rhoads et al. 1978). Although organic enrichment provides a supplementary food source for benthic invertebrate fauna, excessive enrichment can cause significant negative shifts in sediment chemistry and benthic community diversity as oxygen becomes depleted (for review see Diaz \& Rosenberg 2008). However, the relative importance of the respective pathways of organic matter degradation are also influenced by the burrowing and irrigation activities of 
the fauna which transport oxygenated water into the sediment profile, thereby enhancing decomposition and the regeneration of nutrients essential for primary productivity (Kristensen et al. 1995). Along these gradients, the depth of oxidised sediments is frequently used as an indicator of net benthic functioning (mixing depth [MD]; Solan et al. 2004a), providing an opportunity to distinguish the relative importance of biodiversity from environmental factors on ecosystem processes.

In the present study, we characterised changes in benthic community composition and sediment parameters associated with a gradient of organic enrichment from a Scottish fish farm and then determined the most important biotic and abiotic variables in mediating the MD along this gradient. Using variance partitioning (Legendre 1993), we used these data to distinguish the relative importance of changes in macrofaunal diversity from the effects of the abiotic environment in mediating a benthic ecosystem process.

\section{MATERIALS AND METHODS}

Faunal sampling and sediment collection. Sampling was conducted in Loch Creran, Scotland, along an organic enrichment gradient related to commercial fish aquaculture (salmon Salmo salar). To characterise the environmental gradient, sediment and macrofaunal samples were collected using a multi-corer from the RV 'Calanus' along a transect of 7 stations ( 50 m apart) away from the area of the fish farm in the direction of the prevailing tidal current. To avoid pseudoreplication, 2 undisturbed cores from each of 5 deployments (internal diameter $=100 \mathrm{~mm}$, depth $=100 \mathrm{~mm}$ ) were used from each station; one for sediment analyses and the other for macrofaunal identification. For analyses of the sediment parameters, the surface sediment $(0$ to $2 \mathrm{~cm})$ was retained from each core $(\mathrm{n}=35)$ and frozen at $-20^{\circ} \mathrm{C}$. The cores for determination of the macrofaunal communities were immediately sieved (500 $\mu \mathrm{m})$. All fauna retained within the sieve were regarded as macrofauna and were fixed in a $10 \%$ formalin $(4 \%$ formaldehyde) solution buffered with Borax (magnesium borate) to which a $1 \%$ Rose Bengal stain was added to aid visual location of the fauna during sorting.

Sediment profile imaging. The depth of oxidised sediments (MD) is affected by a combination of abiotic and biotic factors and is frequently used as an indicator of net benthic functioning (Solan et al. 2004a) that is related to the richness, abundance and biomass of fauna (e.g. Pearson \& Rosenberg 1978) as well as the rate of organic matter decomposition and nutrient regeneration (Kristensen 2000). The MD can be quantified (for review see Teal et al. 2008) using sediment profile imaging (SPI), a standard technique for deter- mining organism-sediment interactions in relation to benthic disturbances (Rhoads \& Germano 1986). An SPI camera was deployed from the RV 'Seol Mara' along the transect to obtain replicate $(n=5)$ sediment profile images $(18.75 \times 28.13 \mathrm{~cm}, 3000 \times 4500$ pixels $)$ from each site $(n=7)$.

Standard image analysis techniques were used to quantify the depth of the MD. Sediment profile images were saved in RGB colour with jpeg compression and analysed using a custom-made, semi-automated macro that runs within ImageJ (Version 1.40), a javabased public domain program (available at http://rsb. info.nih.gov/ij/index.html). The green slice of the image is most suitable for visual discrimination of the sediment-water interface, which was manually traced with the segmented line tool. The segmented line represented the upper limit of the region of interest for the subsequent analyses. The red slice of the image was then used to distinguish the oxidised (high reflectance) from the reduced (low reflectance) sediment, by manually setting the appropriate threshold for each image (Solan et al. 2004b), and the total area $\left(\mathrm{cm}^{2}\right)$ and mean depth $(\mathrm{cm})$ of the MD were automatically calculated.

Macrofaunal identification, enumeration and biomass determination. Following preservation with formaldehyde, all macrofauna samples were stored in sealed jars and plastic buckets at ambient temperature in the dark to allow the biomass to stabilise. All taxa were identified to the lowest possible taxon $(60.75 \%$ species, $10.28 \%$ genus, $9.35 \%$ family, $19.63 \%$ other).

For the estimation of biomass, the fauna were blotted dry with absorbent paper to remove excess liquid before wet weight determination ( $g$, Ohaus Adventurer Pro 5-figure balance). All tube-dwelling worms (e.g. Owenia fusiformes, Melinna palmata) and hermit crabs Anapagurus laevis were removed from their tubes and shells, respectively, prior to weighing. Due to their small sizes, all bivalves and gastropods were weighed including their shells. For each replicate core the total abundance and total biomass is expressed as per $\mathrm{m}^{2}$ equivalents.

Sediment characteristics. Sediment particle size (mean particle size in $\mu \mathrm{m}$ ) was determined optically using a Malvern Mastersizer X He-Ne LASER diffraction particle sizer (Malvern Instruments) from $5 \mathrm{~g}$ wet weight of surface sediment ( $\mathrm{n}=5$ per station). To establish the quality of the organic material along the gradient, total nitrogen and carbon concentrations were determined using $0.22 \pm 0.02 \mathrm{~g}$ of dried, ground sediment using a Fisons NA 1500 NCS-Analyser (Fisons Instruments) (Allen 1989). In addition, the total organic carbon concentration (TOC, \%) of the sediment was determined by loss on ignition of $1.05 \pm$ $0.01 \mathrm{~g}$ of dry sediment after combustion for $1 \mathrm{~h}$ at $525^{\circ} \mathrm{C}$. Further, we determined total phosphorus (TP, 
$\mathrm{mg} \mathrm{g}^{-1}$ ) and total copper $\left(\mathrm{TCu} \mathrm{mg} \mathrm{g}^{-1}\right)$ concentrations of the surface sediments using a sulphuric acid/hydrogen peroxide digestion of $0.1 \pm 0.001 \mathrm{~g}$ dried ground sediment. TP concentration of the acid digest was determined colorimetrically using a flow injection autoanalyser (FIA Star 5010 with a 5023 spectrophotometer, Tecator) at a detection wavelength of $690 \mathrm{~nm}$. $\mathrm{TCu}$ concentration was determined by atomic absorption spectrometry (Perkin Elmer AAnalyst 100) at a detection wavelength of $324.8 \mathrm{~nm}$ (Allen 1989).

Statistical analyses. A multiple-linear regression model was developed to determine the relative effects of abiotic and biotic variables on the MD along the gradient of impact. The abiotic explanatory variables included TOC, C:N, mean grain size diameter, TP and TCu and station, whilst the biotic explanatory variables were species richness, abundance (ind. $\mathrm{m}^{-2}$ ) and biomass $\left(\mathrm{g} \mathrm{m}^{-2}\right)$. In order to reduce the spread in data within the biotic explanatory variables, abundance and biomass were $\log _{\mathrm{e}^{-}}$ and square root-transformed, respectively. In addition, the abiotic explanatory variables (TOC, grain size, TP and $\mathrm{TCu}$ ) were standardised (z-scores) by centering each variable around its mean across the gradient and dividing by the standard deviation. Standardisation of the variables in this way eliminates size differences between explanatory variables and reduces their variability to a common scale (Legendre \& Legendre 1998, Gelman \& Hill 2007). All explanatory variables, except for station, were included as continuous variables in the initial model, which contained only single terms. The variable station was included as a nominal explanatory variable $(n=7)$. Interactions were not included in the model at this stage, as the sample size relative to the number of explanatory variables was insufficient (see Gelman \& Hill 2007).

Graphical exploratory techniques were used to check for outliers, normality and collinearity of data prior to analysis. Normality was determined by plotting the theoretical quantiles versus the standardised residuals (Q-Q plots) and homogeneity of variance was evaluated by plotting the residuals versus the fitted values. Collinearity was assessed by plotting a scatter plot matrix with associated correlation coefficients, as well as by calculating the variance inflation factor (VIF) for each explanatory variable (Quinn \& Keough 2002). Removal of explanatory variables was based on a conservative level of collinearity (Pearson's correlation coefficient $r>0.6$ and VIF $>5$ ). Species richness and station were strongly collinear $(r=0.91)$ (Fig. S1 in the supplement, available as MEPS Supplementary Material at: www.int-res.com/articles/suppl/m396p273_app.pdf). As our focus was to determine the importance of biodiversity on $\mathrm{MD}$, we retained species richness but removed station from the analysis (MacNally 2000). The VIF value for species richness (VIF $=5.52)$ and the scat- ter plot matrix (Fig. S2 in the supplement) further indicated that species richness was also collinear with other explanatory variables (biomass, $\mathrm{TCu}, \mathrm{TP}$ ). The removal of species richness as an explanatory variable, however, was not appropriate, as doing so would negatively affect the residual pattern of the linear regression model. Therefore, biomass, TCu and TP were removed from the analysis. An influential data point $(n=1, \operatorname{Stn} 2)$ that unduly influenced the estimated regression parameters (slope and intercept) was identified using dfbeta and Cook's distance and was removed (Fox 2002, Quinn \& Keough 2002). A reanalysis with $100 \%$ of the data did not alter the conclusions of the present study, but resulted in a weaker model. Violation of independence of the residuals through spatial autocorrelation between sampling stations was investigated using a bubble plot in which the residuals of the model are plotted against the spatial coordinates of the stations (Zuur et al. 2009). The minimal adequate model was determined using a stepwise backward model selection procedure on a model that included all of the remaining explanatory variables (species richness, abundance, TOC, C:N) as single terms. Model selection was based on Akaike's information criterion (AIC) (Quinn \& Keough 2002) and validated by visual inspection of plots of residuals versus fitted values. This procedure is known to perform similarly to other exhaustive algorithms for subset selection (Murtaugh 2009) and retained species richness and TOC as explanatory variables. Nevertheless, in order to ensure that the selection procedure was robust, we confirmed selection using hierarchical partitioning (Fig. S3 in the supplement), Mallow's $C_{p}$ (Fig. S4 in the supplement) and adjusted $\mathrm{r}^{2}$ (Table $\mathrm{S} 1$ in the supplement) (Draper \& Smith 1998, Quinn \& Keough 2002). The presence of interactive effects between species richness and TOC on the MD was investigated using a co-plot and the interaction was subsequently included in the model. Thus, the minimal adequate model best describing how and which variables mediate the MD consisted of the factors species richness and TOC as single terms and also included the interaction species richness $\times$ TOC.

In order to partition the effects of species richness from the effect of TOC on MD, a partial linear regression analysis was used (Legendre 1993, Legendre \& Legendre 1998). Partial linear regression allows estimation of how much of the variation in MD can be exclusively attributed to species richness and TOC. However, this procedure assumes that effects are additive and therefore the interaction (species richness $x$ TOC) was removed from the minimal adequate model. The amount of variation attributed to either explanatory variable is determined by regressing each explanatory variable against the response variable in the absence of the other explanatory variable. Using 
the procedures detailed in Legendre \& Legendre (1998), the total variation in MD is thus partitioned into the following components: (1) the variance explained by species richness alone, (2) the variance explained by TOC alone, (3) the amount of shared variance explained by species richness and TOC and (4) the amount of unexplained variation.

All analyses were performed using the 'hier.part' (Walsh \& Mac Nally 2008), 'wle' (Agostinelli 2006) and 'nlme' (Pinheiro et al. 2009) packages in the ' $\mathrm{R}$ ' statistical and programming environment (R Development Core Team 2007). Data are presented as means \pm SD unless otherwise indicated.

\section{RESULTS}

\section{Description of the biotic and abiotic gradient}

The mean MD progressively decreased along the gradient from $6.1 \pm 0.6 \mathrm{~cm}$ at $\mathrm{Stn} 1$ furthest away from the fish farm to $2.9 \pm 0.5 \mathrm{~cm}$ at $\operatorname{Stn} 7$ at the fish farm (Fig. 1, Fig. S5 in the supplement for sediment profile images). Sediment TOC, C:N, TP and TCu content increased, whilst sediment grain size decreased from Stn 1 to 7 (Fig. 2). The mean TOC content of the sediment increased from $6.7 \pm$ $1.5 \%$ (Stn 1) to $19.4 \pm 5.0 \%$ (Stn 7), whilst the mean TP content increased from $1.6 \pm 0.1 \mathrm{mg} \mathrm{g}^{-1}$ (Stn 1) to $13.6 \pm$ $3.8 \mathrm{mg} \mathrm{g}^{-1}(\operatorname{Stn} 7)$ and the mean TCu content increased from $0.02 \pm 0.004 \mathrm{mg} \mathrm{g}^{-1}$ (Stn 1) to $0.30 \pm 0.012 \mathrm{mg} \mathrm{g}^{-1}$
(Stn 7). The increase in TOC coincided with an overall reduction in sediment quality (higher $\mathrm{C}: \mathrm{N}$ ) along the gradient and a decrease in the mean particle size from $79.28 \pm 4.4 \mu \mathrm{m}$ at $\operatorname{Stn} 1$ to $29.3 \pm 10.7 \mu \mathrm{m}$ at $\operatorname{Stn} 6$.

Along the environmental gradient, there were distinct changes in benthic macrofaunal species composition, abundance and biomass (Fig. 3). Species richness

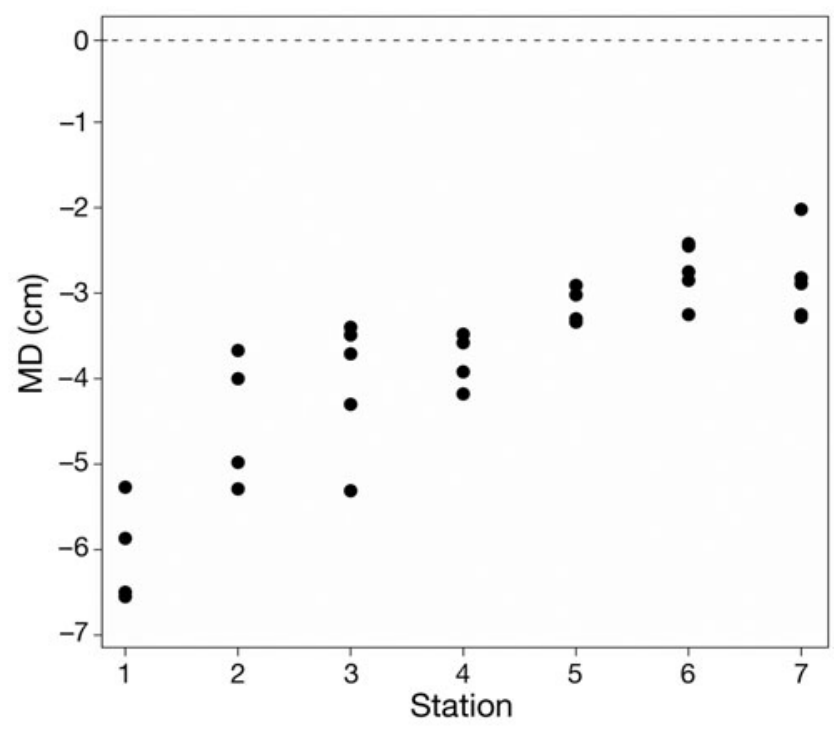

Fig. 1. Mixing depth (MD, $\mathrm{cm})$ at each station along the enrichment gradient, with Stn 1 being furthest away from the fish farm and Stn 7 at the fish farm. Negative values correspond to increasing $\mathrm{MD}$ and the dotted line represents the sediment-water interface
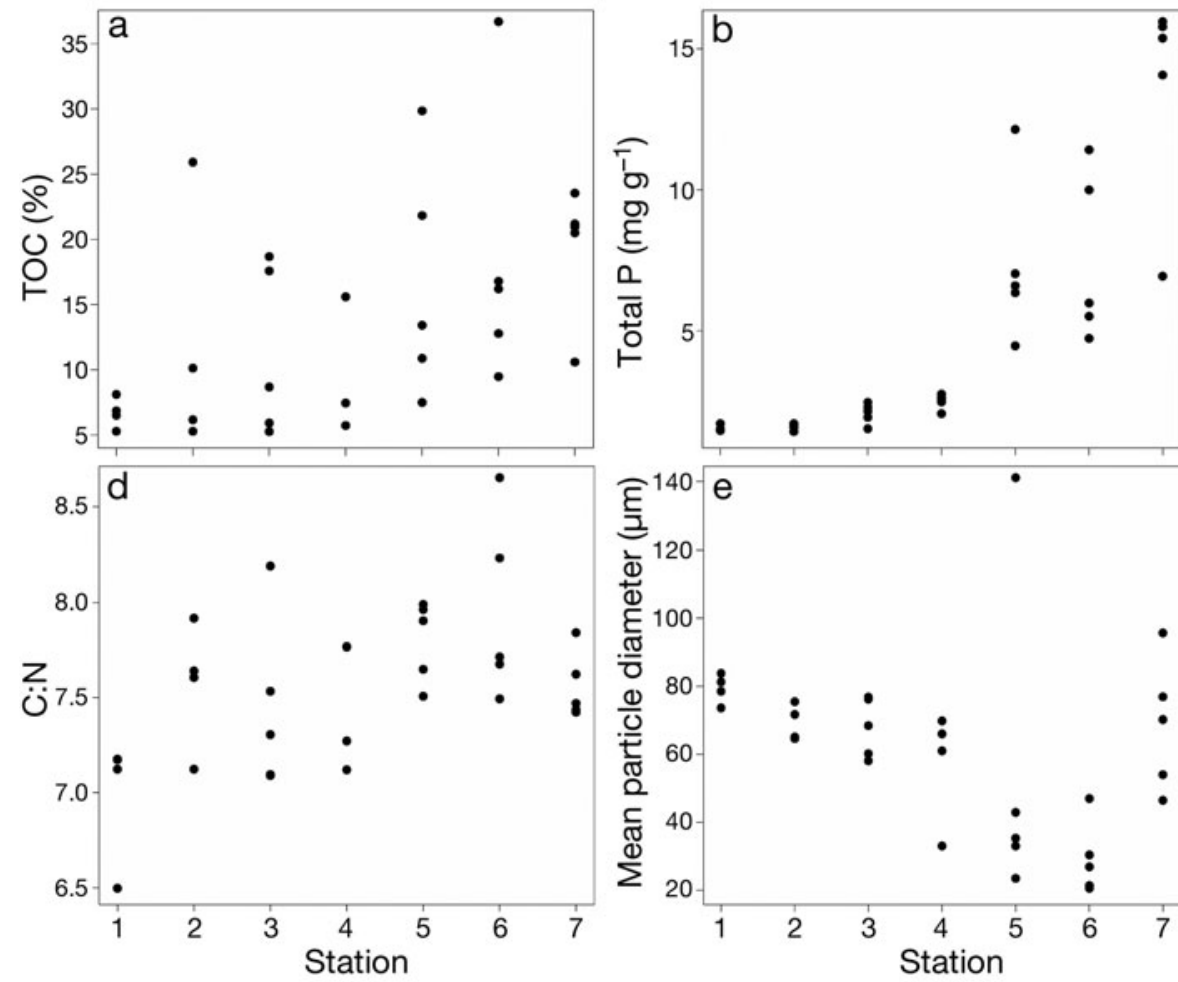

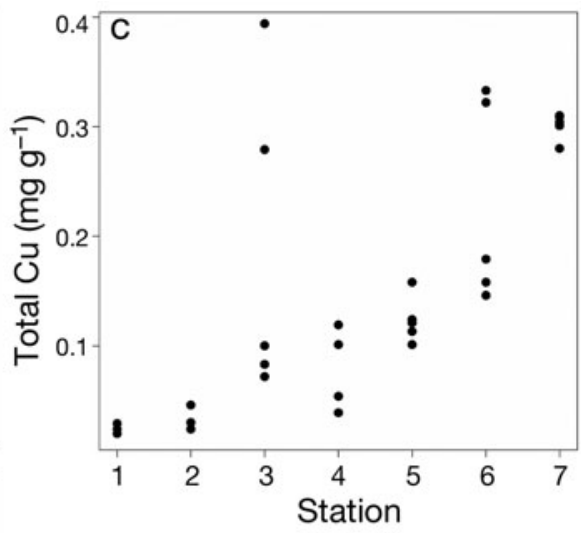

Fig. 2. Abiotic parameters of the surface sediment for each station along the gradient of organic enrichment. TOC: total organic carbon; P: phosphorus; $\mathrm{Cu}$ : copper; $\mathrm{C}: \mathrm{N}$ : carbon to nitrogen ratio 
decreased from $30 \pm 4$ species at Stn 1 to $6 \pm 3$ species at Stn 7 (Fig. 4a). Mean species abundance $(n=5)$ was lowest at Stn $3\left(7028.3 \pm 916.7\right.$ ind. $\left.\mathrm{m}^{-2}\right)$ and highest at Stn 1 (16 $042.8 \pm 5074.6$ ind. $\mathrm{m}^{-2}$ ) (Fig. 4b). In terms of abundance, Stns 5-7 were dominated by the polychaetes Eunicidae spp., Capitella capitata (Capitellidae), Heteromastus filiformis (Capitellidae) and Malacoceros fulinginosus (Spionidae), whilst Stns 1 and 2 were dominated by the mollusc Mysella bidentata (Bivalvia) and the polychaetes Prionospio flallax (Spionidae) and Melinna palmata (Ampharetidae). At Stn 3 the faunal assemblage was dominated by $H$. filiformis, an unidentified nemertean and $M$. bidendata, whilst Stn 4 was dominated by the polychaetes $C$. capitata and $H$. filiformis as well as the same unidentified nemertean as at Stn 3.

Mean total faunal biomass $(n=5)$ was highest at Stn $1\left(226.9 \pm 198.8 \mathrm{~g} \mathrm{~m}^{-2}\right)$ and lowest at Stn 5 (9.6 \pm
$5.6 \mathrm{~g} \mathrm{~m}^{-2}$ ), increasing to $102.8 \pm 211.2 \mathrm{~g} \mathrm{~m}^{-2}$ at $\operatorname{Stn} 7$ (Fig. 4c). The mollusc Philine aperta (Philinidae) and the polychaete Notomastus latericeus (Capitellidae) were dominant species in terms of biomass at the majority of stations along the gradient, exceeding $40 \mathrm{~g}$ $\mathrm{m}^{-2}$ at Stns 2, 3 and 4 for P. aperta and Stn 3 for $N$. latericeus. Stns 1 and 2 were associated with a high biomass of the anthozoans Pennatula phosphorea (Pennatulidae, Stn 1) and Virgularia mirabilis (Virgulariidae, Stn 2), the echinoderm Amphiura filformis (Amphiuridae) as well as the polychaete Melinna palmata. Stn 3 was dominated by $N$. latericeus, $P$. aperta and Terebellides stroemi (Terebellidae), whilst at Stns 4 and 5 P. aperta was the dominant species. Stns 6 and 7 were dominated by the polychaetes Neanthes (Nereis) irrorata (Nereidae) and Malacoceros fulinginosus (Spionidae).

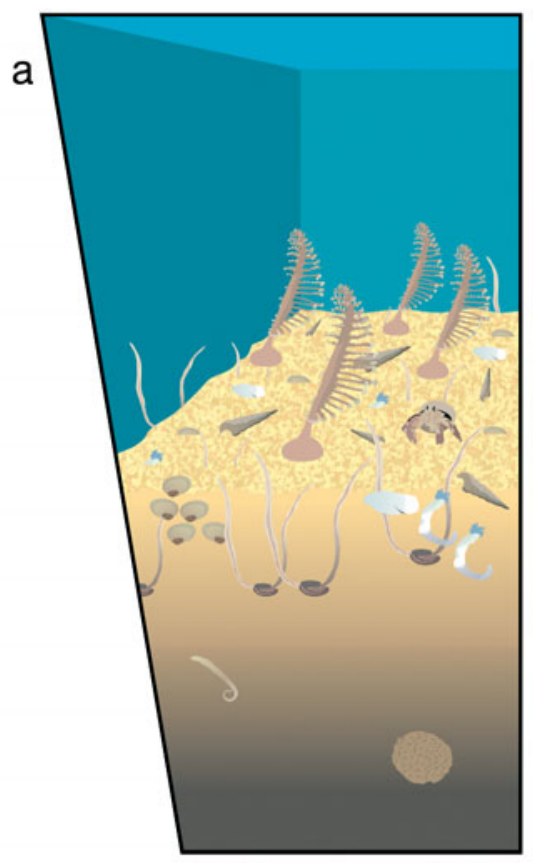

b

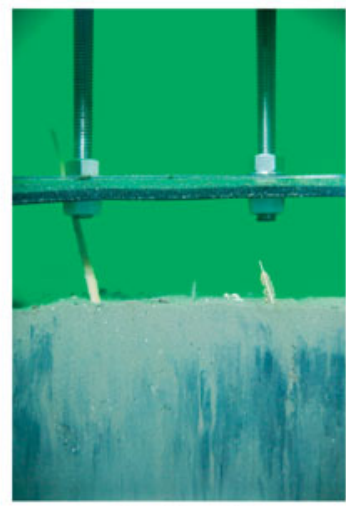

Station 1
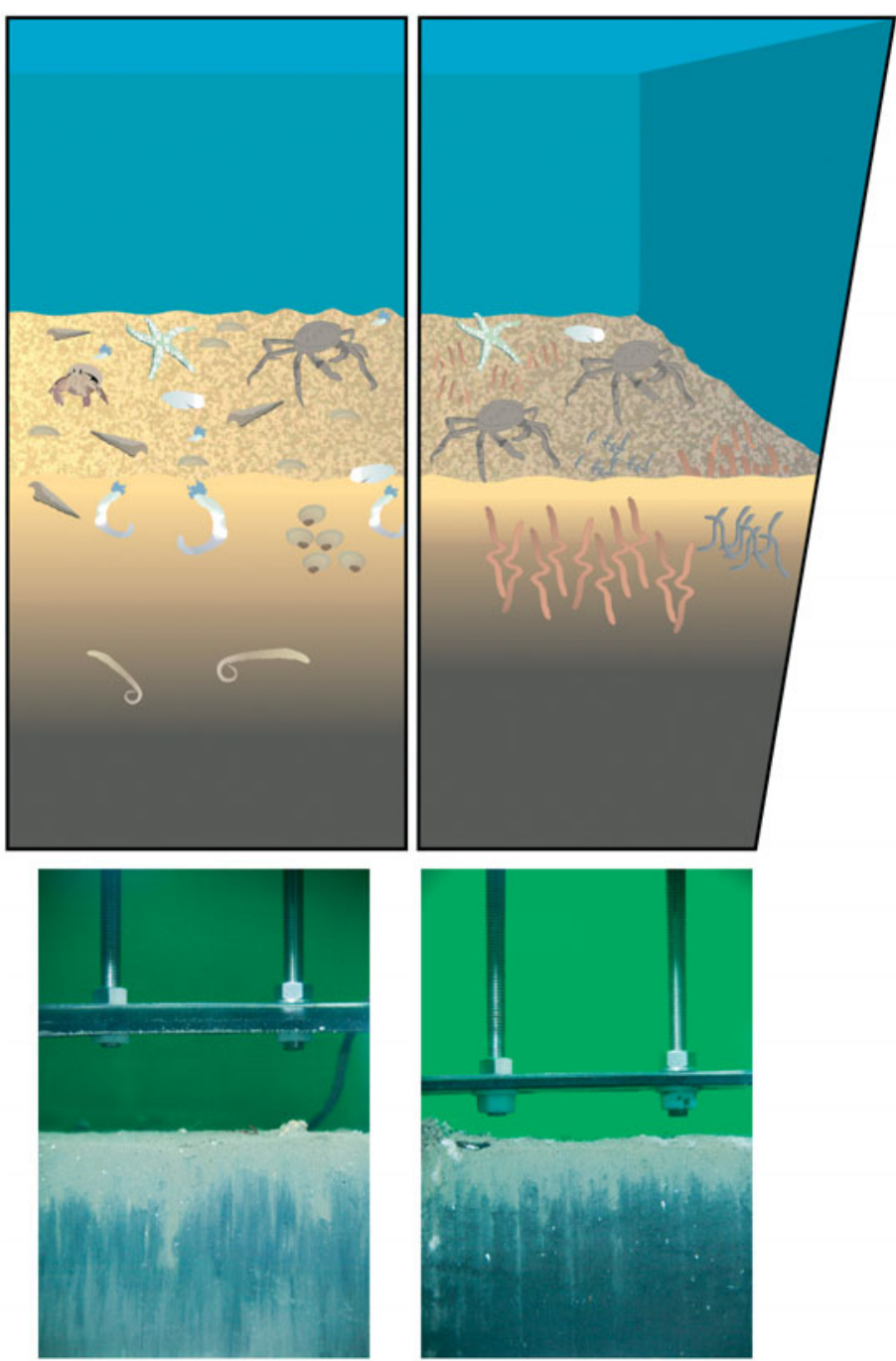

Station 4

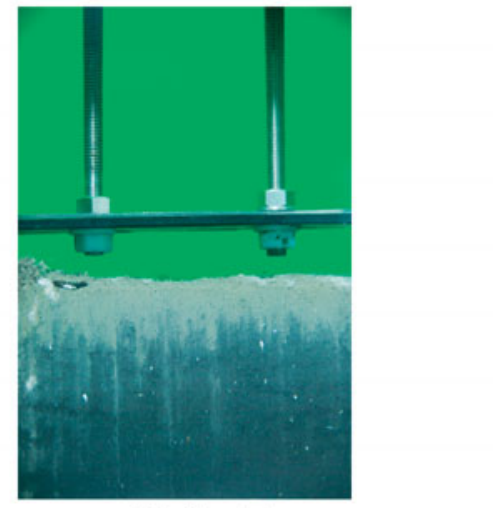

Station 7

Fig. 3. (a) Schematic representation of the changes observed in macrofaunal community composition with increasing organic enrichment and (b) corresponding sediment profile images at Stns 1, 4 and 7. Note that the mixing depth (light brown sediment) and macrofaunal diversity decrease with proximity to the fish farm (Stn 7). In (b) image width $=18.75 \mathrm{~cm}$ 

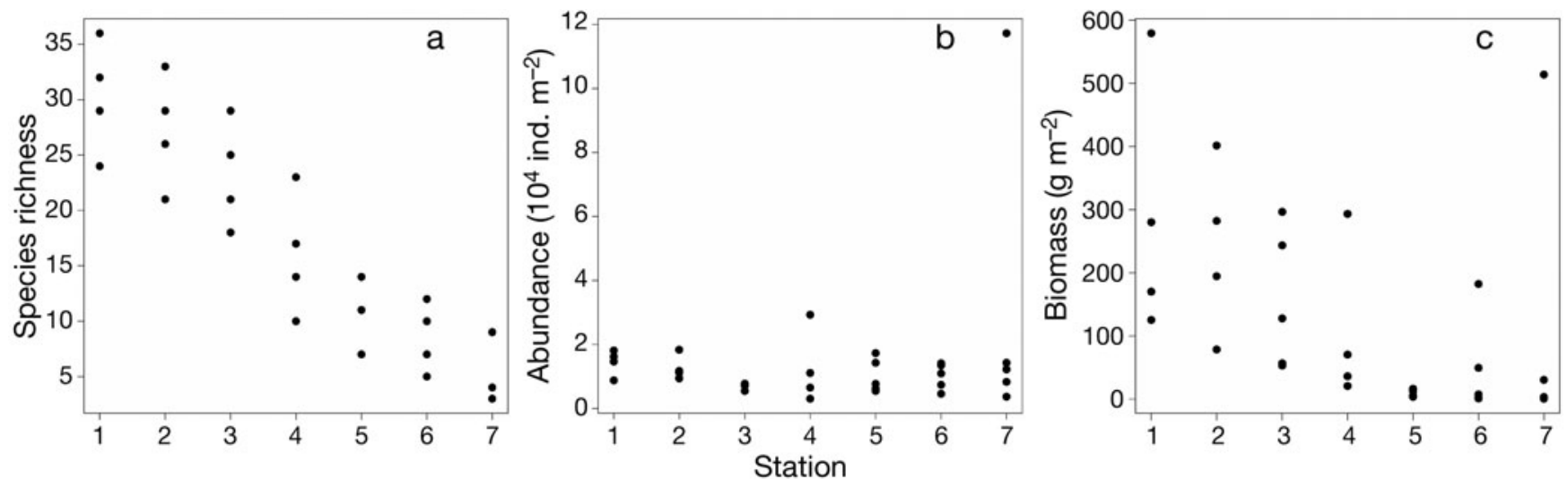

Fig. 4. Summary of macrofaunal returns from 5 replicate cores expressed as (a) species richness, (b) abundance and (c) biomass for each station along the gradient of increasing organic enrichment

\section{Effects of the biotic and abiotic environment on MD}

The minimal adequate model was a linear regression containing species richness $(F=58.70, \mathrm{df}=1, \mathrm{p}<0.0001)$, TOC $(F=5.00, \mathrm{df}=1, \mathrm{p}<0.05)$ and the interaction species richness $\times$ TOC $(F=7.37, \mathrm{df}=1, \mathrm{p}<0.05)$ and explained $72 \%$ of the total variation in $\operatorname{MD}(F=23.69, \mathrm{df}=$ $27, \mathrm{p}<0.0001$ ). At low levels of TOC (for standardised TOC $<0$, Fig. 5) the MD increased strongly with species richness. As TOC concentration increased (for standardised TOC $>0$, Fig. 5), the effect of high species diversity on MD decreased. Overall, there was a positive effect of species richness on MD in all but the most enriched stations (for standardised TOC $>2.0$ ).

\section{Partitioning the effects of the biotic and abiotic environment on MD}

Species richness and TOC, as main terms, together explained $64.96 \%$ of the total variability in $\mathrm{MD}(F=25.95$, $\mathrm{df}=28, \mathrm{p}<0.0001)$. MD increased with species richness (coefficient $\pm \mathrm{SE}=0.08$ $\pm 0.02, t=5.192, \mathrm{p}<0.0001)$, whilst TOC had a marginal negative effect on $\mathrm{MD}$ (coefficient $\pm \mathrm{SE}=-0.03 \pm 0.15, t=$ $-2.019, p=0.053)$. Partial linear regression revealed that over half of the explained variation in MD was attributed to species richness $(33.74 \%$ of total variation), whilst $5.1 \%$ of the total variation was attributed purely to TOC. Less than half $(26.12 \%$ of total variation) of the explained variation in MD was shared between species richness and TOC. Overall, $35.04 \%$ of the total variation in MD could not be explained by species richness or TOC (Fig. 6).

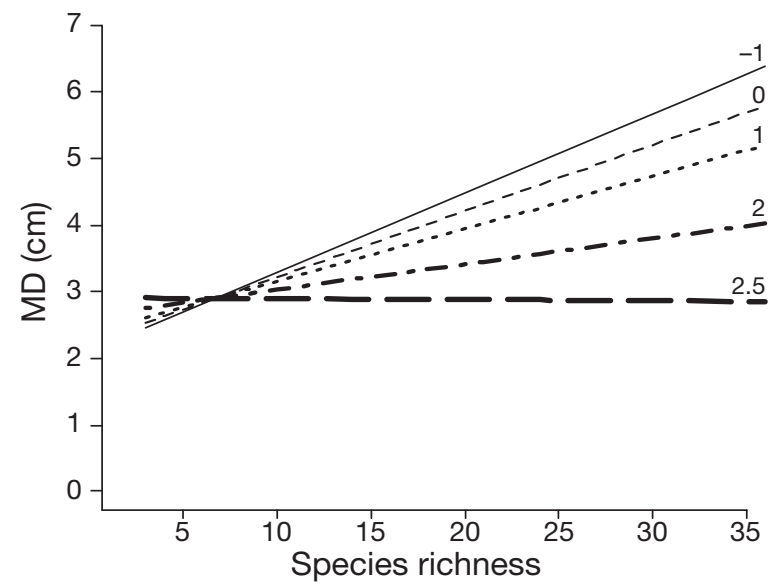

Fig. 5. Effect of species richness and total organic carbon (TOC) on mixing depth (MD, cm). The lines represent model predictions of the interaction species richness $\times$ TOC for different levels of TOC centered on the mean across the gradient (mean $=0$, negative represents lower than mean TOC content and positive represents higher than mean TOC content). $\mathrm{MD}=0$ represents the sediment-water interface
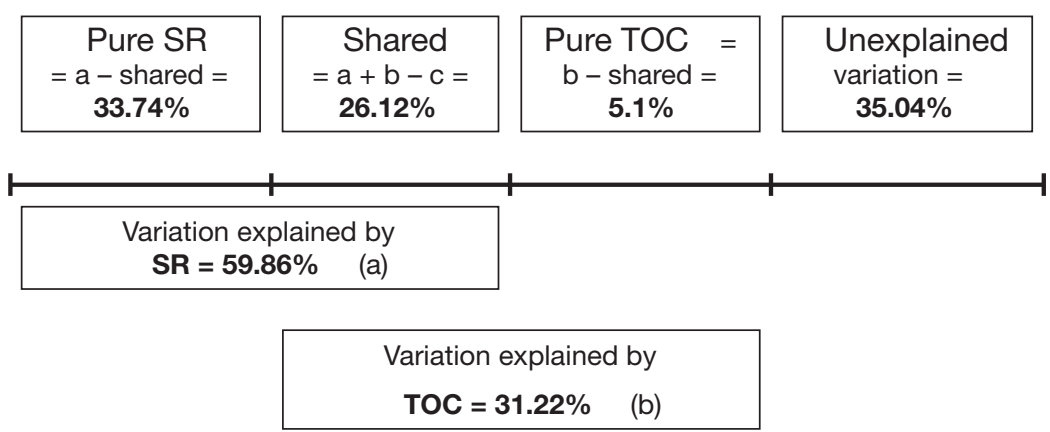

Total explained variation $=64.96 \% \quad$ (c)

Fig. 6. Graphical summary of the partitioning of the variability in MD among the explanatory variables species richness (SR) and total organic carbon (TOC, $\%$ ). Percentages represent the $\mathrm{R}^{2}$ from the partial linear regression models. Adapted from Legendre \& Legendre (1998) 


\section{DISCUSSION}

The present study has successfully documented changes in macrofaunal community composition, physicochemical sediment characteristics and net benthic ecosystem functioning that were associated with an anthropogenic gradient of disturbance. The observed patterns are consistent with what would be expected from benthic successional paradigms (Pearson \& Rosenberg 1978, Rhoads et al. 1978), with the number of species and organic carbon input being the most important factors affecting the MD. Despite the presence of a natural covariance between shifts in community structure and changing environmental factors, the relative importance of TOC and species richness, and their shared contribution, in affecting ecosystem functioning have been determined and together explain the majority ( $65 \%$ ) of the variability in $\mathrm{MD}$.

In contrast to previous studies (e.g. Grace et al. 2007, Healy et al. 2008), changes in species richness accounted for $34 \%$ of the total variability in an ecosystem process (here, MD), whilst environmental factors (here, TOC) had a much lower explanatory power, contributing to only $5 \%$ of the total variability, despite the presence of a strong organic enrichment gradient. The relative weighting of these findings contradict numerous observational studies that suggest that ecosystem functioning will be influenced more by abiotic conditions than by species diversity (e.g. Wardle et al. 1997, Thompson et al. 2005, Grace et al. 2007). Empirical studies, however, have demonstrated that the magnitude of species richness effects may be dependent upon how species interact with the environment; plant species mixtures only have a positive effect on ecosystem functioning if, for example, environmental conditions (e.g. light and soil fertility) allow for mechanisms such as resource partitioning (e.g. Fridley 2002). Such modifying effects of environmental conditions on the relationship between biodiversity and ecosystem functioning have, in the past, largely been attributed to changes in the behaviour and/or relative dominance of individuals within an assemblage (e.g. Cardinale et al. 2000, Bulling et al. 2008, Healy et al. 2008).

A cursory examination of the results of the present study would suggest that enhanced species richness is only important for ecosystem functioning at low levels of organic enrichment, presumably because the environment is less hostile and contains higher species diversity. Yet our model predictions suggest that even at elevated levels of organic enrichment species richness is still of fundamental importance in positively affecting ecosystem functioning. Only at very high levels of organic enrichment, or at low levels of species richness $(<10)$, do environmental drivers become more important in modifying ecosystem processes. If these effects are widespread, such findings have profound implications for field experiments in which diversity is directly manipulated and the species used represent only a subset of the total community (Bulling et al. 2006), because environmental factors are likely to have a stronger effect on ecosystem processes than biodiversity. In fact, meta-analyses provide supporting evidence that species diversity effects tend to be weaker in experimental systems with low levels of diversity $(<10$ species as the highest diversity level) and in less well-controlled systems (Balvanera et al. 2006), where other environmental factors are likely to be contributing to ecosystem properties (Balvanera et al. 2006, Romanuk et al. 2009). Many in situ experiments that have manipulated species diversity and acknowledged the potential effects of environmental factors often assert that abiotic effects (litter quality and temperature, Lecerf et al. 2007; environmental heterogeneity, Healy et al. 2008; nutrient availability, Godbold et al. 2009) are likely to be stronger determinants of ecosystem processes than species diversity.

The present study is the first to quantitatively document, in a natural system and in the presence of a gradient of non-random species loss, that the importance of abiotic influences on an ecosystem process decreases as the full suite of biodiversity is realised. The absolute importance of species diversity in maintaining ecosystem functioning is related to functional characteristics, such as body size, sediment reworking mode and mobility, and how these relate to an individual species' risk of extinction (Solan et al. 2004a). The loss (or decrease in abundance) of species associated with increased organic enrichment and sediment anoxia tends to include those species which have the strongest effects on sediment particle redistribution and porewater chemistry (Diaz \& Rosenberg 2008). This is because, in the absence (or reduction in abundance) of these key bioturbating and bioirrigating species, oxygen penetration is limited and microbes begin to utilise other less efficient electron acceptors (e.g. $\mathrm{NO}_{3}^{-}, \mathrm{SO}_{4}{ }^{2-}, \mathrm{MnO}_{4}, \mathrm{FeOH}$ and $\mathrm{CO}_{2}$ ). These are reduced to metabolites $\left(\mathrm{N}_{2}, \mathrm{HS}^{-}, \mathrm{Mn}^{2+}, \mathrm{Fe}^{2+}\right.$ and $\mathrm{CH}_{4}$, respectively) which can be highly toxic to benthic fauna, leading to further reductions in the abundance and richness of deeper dwelling bioturbators (Aller 1994). Here, the most susceptible species to the effects of enhanced organic enrichment are also those species with traits that are important for bioturbation and bioirrigation (Solan et al. 2004a), including the echinoderm Amphiura filiformis, the bivalves Mysella bidendata and Thyasira flexulosa as well as the tubedwelling or burrowing polychaetes Melinna palmata, Magelona filiformis, Leitoscoloplos mammosus and Lumbrineris tetaura. Even substantial increases in 
abundance (>15000 ind. $\mathrm{m}^{-2}$ ) of Capitella sp., which have smaller body sizes and have less impact on the redistribution of particles and/or porewater fluids, cannot compensate for the loss of larger bioturbating species because the negative effects of the organic enrichment on sediment chemistry outweigh the effects of the surviving species on the mixing depth. This underlying reciprocal relationship between the abiotic and biotic components of the system (Hughes et al. 2007) accounts for almost half of the explained variability in an ecosystem process, but is rarely incorporated into experimental designs (e.g. Bulling et al. 2008). Although the relevance and applicability of biodiversity-ecosystem functioning studies has improved by incorporating environmental realism (Godbold 2008, Naeem 2008, Solan et al. 2009), it is clear that the next generation of biodiversity experiments needs to explicitly incorporate, rather than control for, the reciprocal relationship between biodiversity and the environment. A greater appreciation of the interdependencies between biodiversity and environmental change (e.g. Hiscock et al. 2004) is an immediate requirement if we are to further our understanding of the ecosystem consequences of biodiversity loss in natural systems.

Acknowledgements. We thank the captain and crew of the RVs 'Calanus' and 'Seol Mara' from the Scottish Association for Marine Science, A. Jamieson and D. Mayor (Oceanlab, University of Aberdeen) for deployment of the SPI camera and R. Kennedy (Martin Ryan Institute, National University of Ireland, Galway) for the sediment particle size analysis. We are also grateful to C. Lee (Medical Illustration, University of Aberdeen) for production of the graphics used to visualise macrofaunal community composition. This work was part funded by a Natural Environment Research Council studentship grant (NER/S/A/1005/13734) to J.A.G. and the EU framework 6 programme entitled Coastal Ocean Benthic Observatories.

\section{LITERATURE CITED}

Agostinelli C (2006) wle: weighted likelihood estimation. Available at www.stats.bris.ac.uk/R/

Allen SE (1989) Chemical analysis of ecological materials, 2nd edn. Blackwell Scientific Publications, Oxford

> Aller RC (1994) Bioturbation and remineralisation of sedimentary organic matter: effects of redox oscillation. Chem Geol 114:331-345

Angermeier PL, Winston MR (1998) Local vs. regional influences on local diversity in stream fish communities of Virginia. Ecology 79:911-927

Balvanera P, Pfisterer AB, Buchmann N, He JS, Nakashizuka T, Raffaelli D, Schmid B (2006) Quantifying the evidence for biodiversity effects on ecosystem functioning and services. Ecol Lett 9:1146-1156

Borcard D, Legendre P, Drapeau P (1992) Partialling out the spatial component of ecological variation. Ecology 73 : 1045-1055

Botkin DB, Malone CR (1968) Efficiency of net primary pro- duction based on light intercepted during the growing season. Ecology 49:438-444

Bulling MT, White PCL, Raffaelli D, Pierce GJ (2006) Using model systems to address the biodiversity-ecosystem functioning process. Mar Ecol Prog Ser 311:295-309

Bulling MT, Solan M, Dyson KE, Hernandez-Milian G and others (2008) Species effects on ecosystem processes are modified by faunal responses to habitat composition. Oecologia 158:511-520

Cardinale BJ, Nelson K, Palmer MA (2000) Linking species diversity to the functioning of ecosystems: on the importance of environmental context. Oikos 91:175-183

Cardinale BJ, Srivastava DS, Duffy JE, Wright JP, Downing AL, Sankaran M, Jouseau C (2006) Effects of biodiversity on the functioning of trophic groups and ecosystems. Nature 443:989-992

Cardinale BJ, Bennett DM, Nelson CE, Gross K (2009) Does productivity drive diversity or vice versa? A test of the multivariate productivity-diversity hypothesis in streams. Ecology 90:1227-1241

Chevan A, Sutherland M (1991) Hierarchical partitioning. Am Stat 45:90-96

> Diaz RJ, Rosenberg R (2008) Spreading dead zones and consequences for marine ecosystems. Science 321:926-929

Draper NR, Smith H (1998) Applied regression analysis, 3rd edn. John Wiley \& Sons, New York

> Duffy JE (2009) Why biodiversity is important to the functioning of real-world ecosystems. Front Ecol Environ 7: 437-444

- Emmerson MC, Solan M, Emes C, Paterson DM, Raffaelli D (2001) Consistent patterns and the idiosyncratic effects of biodiversity in marine ecosystems. Nature 411:73-77

Flint RW, Kalke RD (2005) Reinventing the wheel in ecology research? Science 307:1875-1876

Fox J (2002) An R and S-Plus companion to applied regression. SAGE Publications, Thousand Oaks, CA

Fridley JD (2002) Resource availability dominates and alters the relationship between species diversity and ecosystem productivity in experimental plant communities. Oecologia 132:271-277

Fukami T, Wardle DA (2005) Long-term ecological dynamics: reciprocal insights from natural and anthropogenic gradients. Proc R Soc B 272:2105-2115

Galbraith HS, Vaughn CC, Meier CK (2008) Environmental variables interact across spatial scales to structure trichopteran assemblages in Ouachita Mountain rivers. Hydrobiologia 596:401-411

Gelman A, Hill J (2007) Data analysis using regression and multilevel/hierarchical models. Cambridge University Press, Cambridge

Godbold JA (2008) Marine benthic biodiversity-ecosystem function relations in complex systems. $\mathrm{PhD}$ thesis, University of Aberdeen, Scotland

> Godbold JA, Solan M, Killham K (2009) Consumer species richness and identity effects on marine macroalgal decomposition. Oikos 118:77-86

Grace JB (2006) Structural equation modelling and natural systems. Cambridge University Press, Cambridge

> Grace JB, Anderson TM, Smith MD, Seabloom E and others (2007) Does species diversity limit productivity in natural grassland communities? Ecol Lett 10:680-689

Graham MH (2003) Confronting multicollinearity in ecological multiple regression. Ecology 84:2809-2815

> Healy C, Gotelli NJ, Potvin C (2008) Partitioning the effects of biodiversity and environmental heterogeneity for productivity and mortality in a tropical tree plantation. J Ecol 96: 903-913 
Hector A, Schmid B, Beierkuhnlein C, Caldeira MC and others (1999) Plant diversity and productivity experiments in European grasslands. Science 286:1123-1127

Hiscock K, Southward A, Tittley I, Hawkins S (2004) Effects of changing temperature on benthic marine life in Britain and Ireland. Aquatic Conserv 14:333-362

Hooper DU, Chapin FS, Ewel JJ, Hector A and others (2005) Effects of biodiversity on ecosystem functioning: a consensus of current knowledge. Ecol Monogr 75:3-35

Hughes AR, Byrnes JE, Kimbro DL, Stachowicz JJ (2007) Reciprocal relationships and potential feedbacks between biodiversity and disturbance. Ecol Lett 10:849-864

Huston MA, McBride AC (2002) Evaluating the relative strengths of biotic versus abiotic controls on ecosystem process. In: Loreau M, Naeem S, Inchausti P (eds) Biodiversity and ecosystem functioning: synthesis and perspectives. Oxford University Press, Oxford

Jolliffe IT (2002) Principal component analysis. SpringerVerlag, New York

> Jones MM, Tuomisto H, Borcard D, Legendre P, Clark DB, Olivas PC (2008) Explaining variation in tropical plant community composition: influence of environmental and spatial data quality. Oecologia 155:593-604

Kristensen E (2000) Organic matter diagenesis at the oxic/ anoxic interface in coastal marine sediments, with emphasis on the role of burrowing animals. Hydrobiologia 426: $1-24$

Kristensen ES, Ahmend SI, Devol AH (1995) Aerobic and anaerobic decomposition of organic matter in marine sediments: Which is fastest? Limnol Oceanogr 40:1430-1437

Lecerf A, Risnoveanu G, Popescu C, Gessner MO, Chauvet E (2007) Decomposition of diverse litter mixtures in streams. Ecology 88:219-227

Legendre P (1993) Spatial autocorrelation: Trouble or new paradigm? Ecology 74:1659-1673

Legendre P, Legendre L (1998) Numerical ecology. Elsevier, Amsterdam

Mac Nally R (2000) Regression and model-building in conservation biology, biogeography and ecology: the distinction between and reconciliation of 'predictive' and 'explanatory' models. Biodivers Conserv 9:655-671

McNaughton SJ (1993) Biodiversity and function of grazing ecosystems. In: Schulze ED, Mooney HA (eds) Biodiversity and ecosystem function. Springer-Verlag, Berlin, p 361-384

Mittelbach GG, Steiner CF, Scheiner SM, Gross KL and others (2001) What is the observed relationship between species richness and productivity? Ecology 82:2381-2396

Murtaugh PA (2009) Performance of several variable-selection methods applied to real ecological data. Ecol Lett 12: 1061-1068

Naeem S (2008) Advancing realism in biodiversity research. Trends Ecol Evol 23:414-416

Pearson TH, Rosenberg R (1978) Macrobenthic succession in relation to organic enrichment and pollution of the marine environment. Oceanogr Mar Biol Annu Rev 16:229-311

Pinheiro J, Bates D, DebRoy S, Sarkar D, R Core team (2009) nlme: linear and nonlinear mixed effects models. www.stats.bris.ac.uk/R/

Quinn QP, Keough MJ (2002) Experimental design and data analysis for biologists. Cambridge University Press, Cambridge

R Development Core Team (2007) R: a language and environ- ment for statistical computing. R Foundation for Statistical Computing, Vienna, available at www.R-project.org

Raffaelli D (2006) Biodiversity and ecosystem functioning: issues of scale and trophic complexity. Mar Ecol Prog Ser 311:285-294

- Rhoads DC, Germano JD (1986) Interpreting long-term changes in benthic community structure: a new protocol. Hydrobiologia 142:291-308

Rhoads DC, McCall PL, Yingst JY (1978) Disturbance and production on the estuarine sea floor. Am Sci 66:577-586

> Romanuk TN, Vogt RJ, Kolasa J (2009) Ecological realism and mechanisms by which diversity begets stability. Oikos 118:819-828

Ross DJ, Tate KR, Newton PCD, Wilde RH, Clark H (2000) Carbon and nitrogen pools and mineralization in a grassland clay soil under elevated carbon dioxide at a natural $\mathrm{CO}_{2}$ spring. Glob Change Biol 6:779-790

Solan M, Cardinale BJ, Downing AL, Engelhardt KAM, Ruesink JL, Srivastava DS (2004a) Extinction and ecosystem function in the marine benthos. Science 306: $1177-1180$

Solan M, Wigham BD, Hudson IR, Kennedy R and others (2004b) In situ quantification of bioturbation using timelapse fluorescent sediment profile imaging (f-SPI), luminophore tracers and model simulation. Mar Ecol Prog Ser 271:1-12

Solan M, Godbold JA, Symstad A, Flynn DFB, Bunker D (2009) Biodiversity-ecosystem function research and biodiversity futures: Early bird catches the worm or a day late and a dollar short? In Naeem S, Bunker DE, Hector A, Loreau M, Perrings C (eds) Biodiversity and human impacts: ecological and societal implications. Oxford University Press, Oxford

Srivastava DS, Vellend M (2005) Biodiversity-ecosystem function research: Is it relevant to conservation? Annu Rev Ecol Evol Syst 36:267-294

Teal LR, Bulling MT, Parker ER, Solan M (2008) Global patterns of bioturbation intensity and mixed depth of marine sediments. Aquat Ecol 2:207-218

Thompson K, Askew AP, Grime JP, Dunnett NP, Willis AJ (2005) Biodiversity, ecosystem function and plant traits in mature and immature plant communities. Funct Ecol 19: $355-358$

Tilman D, Naeem S, Knops J, Reich P and others (1997) Biodiversity and ecosystem properties. Science 278:1865-1869

Troumbis AY, Memtsas D (2000) Observational evidence that diversity may increase productivity in Mediterranean shrublands. Oecologia 125:101-108

Vitousek PM, Turner DR, Parton WJ, Sanford RL (1994) Litter decomposition on the Mauna Loa environmental matrix, Hawaii'i: patterns, mechanisms and models. Ecology 75: 418-429

Walsh C, Mac Nally R (2008) hier.part: hierarchical partitioning. Available at www.stats.bris.ac.uk/R/

Wardle DA, Zackrisson O, Hörnberg G, Gallet C (1997) The influence of island area on ecosystem properties. Science 277:1296-1299

Worm B, Barbier EB, Beaumont N, Duffy JE and others (2006) Impacts of biodiversity loss on ocean ecosystem services. Science 314:787-790

Zuur AF, Ieno EN, Walker N, Smith GM (2009) Analysing ecological data using mixed modelling and extensions in $\mathrm{R}$. Springer, New York 